\title{
Literatura sobre biblioteca escolar: características de citações de teses e dissertações brasileiras
}

\section{Literature on pertaining to school library: Brazilian citation characteristics of theses and dissertations}

\author{
Bernadete Santos CAMPELLO \\ Márcia Milton VIANNA² \\ Paulo da Terra CALDEIRA ${ }^{3}$ \\ Vera Lúcia Furst Gonçalves ABREU4 \\ Maria da Conceição CARVALHO ${ }^{5}$ \\ Adriana Costa e Silva BENIGNO6
}

RESUMO

A análise de citações de 28 teses e dissertações sobre biblioteca escolar produzidas no Brasil teve como objetivos: identificar influências de autores e de áreas do conhecimento, características de citação e diferenças entre teses e dissertações. Não foi possível verificar relações entre autores, já que houve grande dispersão em termos dos cursos de origem e dos documentos citados. Foi possível identificar significativa influência da Educação. A comparação entre teses e dissertações não evidenciou diferenças significativas, esperadas em textos que resultam de níveis diferentes de formação acadêmica. Foram verificadas, entre outras, as seguintes características das citações: predominância do livro, de documentos de autoria individual, de trabalhos em português e oriundos do Brasil e de periódicos brasileiros nas citações.

Palavras-chave: análise de citação; biblioteca escolar; teses e dissertações.

\section{A B S T R A C T}

The citation analysis of 28 theses and dissertations on school library produced in Brazil aimed at identifying: influences of authors and areas, citation characteristics and differences between theses and dissertations. It was not possible to identify relations between authors, due to great dispersion in terms of the institutions of origin and

\footnotetext{
1 Mestre, Escola de Ciência da Informação, Universidade Federal de Minas Gerais. Av. Antônio Carlos, 6627, 31270-901, Belo Horizonte, MG, Brasil. Correspondência para/Correspondence to: B.S. CAMPELLO. E-mail: <campello@eci.ufmg.br>.

2 Mestre, Escola de Ciência da Informação, Universidade Federal de Minas Gerais. Belo Horizonte, MG, Brasil. E-mail: <marciamilton@eci.ufmg.br>.

${ }^{3}$ Mestre, Escola de Ciência da Informação, Universidade Federal de Minas Gerais. Belo Horizonte, MG, Brasil. E-mail: <terra@eci.ufmg.br>.

${ }^{4}$ Especialista, Escola de Ciência da Informação, Universidade Federal de Minas Gerais. Belo Horizonte, MG, Brasil. E-mail: <veralucia@eci.ufmg.br>.

5 Mestre, Escola de Ciência da Informação, Universidade Federal de Minas Gerais. Belo Horizonte, MG, Brasil. E-mail: <daccar@gmail.com>.

- Bolsista de IC (FAPEMIG), Escola de Ciência da Informação, Universidade Federal de Minas Gerais, Belo Horizonte, MG, Brasil. Email: <drica3d@gmail.com>.

Recebido em 14/1 1/2007 e aceito para publicação em 19/7/2007.
} 
of cited documents. It was possible to identify significant influence of Education. The comparison between theses and dissertations did not show significant differences, expected in documents that result from different levels of academic education. Some characteristics in citing could be identified: predominance of the book, of citations of individual authorship, of documents in Portuguese and published in Brazil and of Brazilian periodicals in the citations.

Keywords: citation analysis; school library; thesis and dissertations.

\section{N T R O D U Ç Ã O}

Os Parâmetros Curriculares Nacionais, documentos do MEC que visam a direcionar as propostas curriculares das escolas brasileiras, entendem que a biblioteca escolar é "[...] a primeira das condições favoráveis para a formação de bons leitores, ao lado do acervo de classe e das atividades de leitura." (Brasil, 1997, p.58). Entretanto, observando-se o panorama educacional brasileiro, verifica-se que são poucas as bibliotecas escolares que têm qualidade para influenciar, de forma significativa, o processo de aprendizagem. Em sua maioria, a biblioteca escolar é um espaço pouco representativo na instituição escolar. Deixando de lado a falta crônica de recursos para criação e manutenção das bibliotecas, já suficientemente explorada pela literatura da área, nela pode-se perceber poucas evidências de embasamento conceitual, ou seja, de reflexão sistemática que sustente a prática pedagógica do bibliotecário.

Análise da literatura realizada por Campello (2003), utilizando documentos produzidos entre os anos de 1961 a 2000, visando a identificar como a função pedagógica da biblioteca escolar se refletia no discurso dos praticantes da área, mostrou não somente que essa função vem-se apresentando de maneira vaga e frágil, mas também que o discurso não consegue explicitar, de maneira clara e objetiva, o papel dessa instituição na escola. $O$ estudo revelou que o trabalho na biblioteca é realizado de forma simplista e pouco consistente e, conseqüentemente, pouco contribui para o processo de aprendizagem, resultando no isolamento da biblioteca no ambiente escolar e no empobrecimento do diálogo do bibliotecário com os educadores.

A fragilidade conceitual desse campo do conhecimento parece ressentir-se do pequeno número de pesquisas publicadas no Brasil até o presente momento. De fato, a biblioteca escolar esteve pouco presente nas agendas de pesquisa no país. A base de dados bibliográfica Literatura em Biblioteca Escolar -
LIBES*, que inclui artigos de periódicos, dissertações, teses e trabalhos apresentados em eventos sobre o tema publicados no Brasil desde a década de 1960, continha, em junho de 2006, 39 trabalhos de pesquisa, num total de 332 referências, o que indica que a biblioteca escolar tem sido um tema pouco atrativo para os pesquisadores.

Nos últimos anos, a ênfase colocada pelos governos na educação e a disseminação das teorias construtivistas acentuaram a necessidade de se buscarem soluções para os problemas de ensino/aprendizagem. A biblioteca é agora relembrada como um recurso que pode contribuir para as ações educativas. Observa-se, entre os especialistas em educação, tendência para propostas de aprendizagem que não se reduzam à dimensão escolar. Isso significa envolver outras instituições culturais como bibliotecas públicas, centros culturais, museus, arquivos, etc. na vida escolar, o que demandaria o uso de métodos flexíveis de aprendizagem. Nessa perspectiva, acredita-se que uma boa biblioteca escolar poderá contribuir para levar crianças e jovens a se familiarizarem e a utilizaremr adequadamente $\mathrm{o}$ aparato informacional oferecido por essas instituições.

Se a biblioteca escolar ressurge no bojo do movimento de valorização da educação, é no sentido de participar do esforço de formação de crianças e jovens, contribuindo para o desenvolvimento de habilidades que facilitem a vivência em ambientes saturados de informações, característicos da sociedade contemporânea. Além disso, deverá preocupar-se em desenvolver competências sociais para que as pessoas sejam capazes de tornar as sociedades mais igualitárias e solidárias (Martucci, 1999). Tudo isso tem levado pesquisadores da área de biblioteconomia e ciência da informação no Brasil a engajarem-se em estudos que buscam entender melhor as questões relativas à biblioteca escolar, e, desde os anos 1970, observa-se a produção de alguns trabalhos acadêmicos sobre $\circ$ assunto, a partir da implantação de cursos de pós-

"Disponível em: http://www.eci.ufmg.br/gebe/index.php?m=L

TransInformação, Campinas, 19(3): p. 227-236, set./dez., 2007 
graduação na área (Vieira, 1990, p.69). Neves (2000) encontrou 14 teses e dissertações $(2,50 \%)$ sobre biblioteca escolar, num total de 556 defendidas em cursos de mestrado e doutorado em biblioteconomia, ciência da informação e documentação, no período de 1975 a 1998, no Brasil.

Esses trabalhos são importantes, pois representam o esforço de pesquisa formal, metodológico, conceitual e original, que vem sendo desenvolvido pelos estudiosos (Ohira et al., 1997, p.76) e, como produto do seu pensamento e reflexão, esse tipo de documento "traz em si marcas de relações com pensamentos e conhecimentos anteriormente registrados sobre a mesma realidade ou objeto estudado" (Alvarenga, 1996, p.81). Tais relações são concretizadas pela prática da citação a outros textos, constituindo um entrecruzamento que "tende a vincular o conhecimento produzido aos conceitos vigentes, numa área específica do conhecimento, atribuindo-lhe chancela de autenticidade" (Alvarenga, 1996, p.82), tendo potencial para permitir a identificação de influências na área, embora sempre haja uma lacuna no conhecimento sobre as razões que levaram um autor a citar determinado trabalho (Macias-Chapula, 1998, p. 136).

O estudo das relações textuais que ocorrem por meio das citações permite traçar estruturas, caminhos e padrões de relações entre áreas, temas e autores, embora não chegue a analisar conteúdos (Alvarenga, 1996, p.87). A análise de citações permite que se identifiquem essas relações, pois está baseada na premissa de que uma citação bibliográfica constitui a expressão de um elo entre dois documentos.

A ciência da informação foi objeto de estudos de citação que revelaram características da literatura da área. Bohn (2003) analisou 86 artigos e os documentos por eles citados, publicados em quatro periódicos brasileiros (Ciência da Informação Online, Encontros BIBLI, DataGramaZero e Transinformação). Os estudos de Población e Noronha (2002) e de Mueller e Pecegueiro (2001) também contribuíram para o conhecimento da área de ciência da informação a partir de sua literatura. De especial interesse para o presente estudo foi a pesquisa de Vianna e Caldeira (2005) que analisaram as citações dos 23 trabalhos selecionados para apresentação, no III Seminário Biblioteca Escolar Espaço de Ação Pedagógica, ocorrido em 2004.
O objetivo do presente estudo é verificar, a partir da análise de citações de teses e dissertações sobre biblioteca escolar defendidas em cursos de pósgraduação no Brasil, algumas características das citações e identificar influências de áreas do conhecimento e de autores, incluindo-se orientadores.

\section{METODOLOGIA}

Pretendeu-se incluir no estudo todas as teses e dissertações, produzidas no Brasil, cuja questão central fosse biblioteca escolar. Em busca realizada em 2005, foram identificados 35 trabalhos nas bases de dados disponíveis nas seguintes universidades: UFMG, UFRJ, UFPB, UFRGS, UnB, UFF, PUC-Campinas e PUC do Paraná. Além disso, foram consultadas a Base de Dados de Teses e Dissertações/IBICT, o Prossiga (CNPq) e o catálogo de teses da coleção Scielo. Foram obtidas cinco teses de doutorado e 23 dissertações de mestrado, representando $80 \%$ do universo. Em seguida, foi feito o levantamento das citações, isto é, das referências constantes nas bibliografias das teses e dissertações, que atingiram um total de 2091. Assim, o corpus documental analisado constituiu-se de 28 trabalhos citantes, dos quais se originaram os 2091 trabalhos citados.

\section{RES U L TA D O S}

\section{Características do corpus documental}

Ano de defesa das teses e dissertações

As 28 teses e dissertações estudadas foram defendidas no período de 1975 a 2002, estando distribuídas conforme mostra o Quadro 1. A distribuição é regular a partir de 1983, exceto nos anos de 1997 e 1998, que concentram um terço dos documentos analisados e de 1992 a 1994, quando não houve produção. 
Quadro 1. Número de teses e dissertações defendidas por ano.

\begin{tabular}{cc}
\hline Ano de defesa & $\mathbf{n}^{\circ}$ de teses e dissertações \\
\hline 1975 & 1 \\
1983 & 2 \\
1985 & 1 \\
1987 & 2 \\
1988 & 1 \\
1989 & 2 \\
1990 & 1 \\
1991 & 2 \\
\hline
\end{tabular}

Instituições e orientadores

Com relação à instituição de origem, pode-se observar pela Tabela 1 a concentração em duas instituições (UFMG e USP), com cinco trabalhos em

\begin{tabular}{cc}
\hline Ano de defesa & $\mathrm{n}^{\circ}$ de teses e dissertações \\
\hline 1995 & 1 \\
1997 & 3 \\
1998 & 6 \\
1999 & 2 \\
2000 & 2 \\
2001 & 1 \\
2002 & 1 \\
\hline Total: & 28 \\
\hline
\end{tabular}

cada uma. As outras 10 instituições de origem foram responsáveis pelos 18 trabalhos restantes, sendo que cinco delas originaram um único trabalho cada, mostrando a pouca representatividade do tema nas linhas de pesquisas dos programas de pós-graduação.

Tabela 1. Teses e dissertações por instituição.

\begin{tabular}{lcc}
\hline \multicolumn{1}{c}{ Instituição (nome) } & $\mathrm{n}^{\circ}$ de & trabalhos \\
\hline UFMG & 5 & 17,9 \\
USP & 5 & 17,9 \\
PUC - RS & 3 & 10,7 \\
PUC - CAM & 3 & 10,7 \\
UNB & 3 & 10,7 \\
UFRN & 2 & 7,1 \\
UFF & 2 & 7,1 \\
UFPB & 1 & 3,6 \\
UNESP & 1 & 3,6 \\
UFPA & 1 & 3,6 \\
UFSC & 1 & 3,6 \\
Universidade Metodista de Piracicaba & 1 & 3,6 \\
\hline Total & 28 & 100,0 \\
\hline
\end{tabular}

As 28 teses e dissertações tiveram 25 professores como orientadores, sendo que um deles orientou três trabalhos e outro orientou dois, havendo uma coorientação. Os demais orientaram um trabalho cada.

\section{Áreas dos programas}

Para definição das áreas de conhecimento dos cursos de origem dos trabalhos, foram consultadas as folhas de rosto dos documentos analisados, mantendose a terminologia ali utilizada e o resultado pode ser visualizado no Quadro 2. Percebe-se concentração em
Educação (com 13 dos 28 trabalhos) e Biblioteconomia (10 trabalhos). Os cinco trabalhos restantes originaramse de cursos de Ciência da Informação (4) e Ciência da Computação (1).

Quadro 2. Área de conhecimento dos cursos de origem.

\begin{tabular}{lc}
\hline \multicolumn{1}{c}{ Área do curso } & $\mathbf{n}^{\circ}$ de \\
\hline Educação & 13 \\
Biblioteconomialhos & 10 \\
Ciência da Informação & 4 \\
Ciência da Computação & 1 \\
\hline Total & 28 \\
\hline
\end{tabular}


Número de trabalhos citados

Foi observada grande variação no número de citações feitas nas teses e dissertações, desde um trabalho com oito citações, a outro com 156, com média de 75 citações por trabalho, maior do que a encontrada no estudo de Vianna e Caldeira (2005), que analisou citações de trabalhos de eventos e que apresentou média de 16 referências por trabalho. Esses resultados estão coerentes com a natureza dos documentos analisados. Comparando teses com dissertações, verificou-se que a média de citações das teses foi de 79,2, ligeiramente mais alta do que a das citações feitas nas dissertações, que foi de 73,7 .

\section{Análise das citações}

Tipologia dos documentos citados

Otipo de documento mais citado foi o livro, representando mais da metade $(52,17 \%)$ das 2091 referências analisadas e em seguida o periódico, com $23,91 \%$ do total. $\bigcirc$ restante das citações $(23,92 \%)$ constituiu-se de uma variedade de tipos de documentos, incluindo desde textos formais, como teses e dissertações $(4,68 \%)$ e publicações governamentais, até documentos informais, como notas de aulas, trabalhos de disciplinas e comunicação pessoal. Houve preferência por uma literatura já mais consolidada, em detrimento de resultados de pesquisas e avanços da área, representados pelos periódicos científicos. Recorte relativo aos documentos eletrônicos revelou sua pouca representatividade: apenas 15 desses documentos foram citados $(0,67 \%)$.

A análise comparativa entre teses e dissertações indicou características de citação similares no que diz respeito à tipologia dos documentos citados.

A predominância de citação de livros já havia sido identificada no estudo de Vianna e Caldeira (2005). Esse material constituiu 59,1\% das citações daquele estudo, que também indicou um uso significativo de artigos de periódicos $(20,5 \%)$, incluídos nesse total os artigos de periódicos eletrônicos.

\section{Autoria}

A maioria dos documentos citados foi de autoria individual $(87,9 \%)$, padrão semelhante ao ocorrido no estudo de Vianna e Caldeira (2005), que encontrou $79,3 \%$ de citações de autoria individual. A quantidade de trabalhos individuais e de autoria múltipla pode ser visualizada na Tabela 2 .

Tabela 2. Número de autores dos documentos citados.

\begin{tabular}{lcr}
\hline \multicolumn{1}{c}{$\mathbf{n}^{\circ}$ de autores } & $\mathbf{n}^{\circ}$ de ref. & $\%$ \\
\hline 1 & 1838 & 87,9 \\
2 & 172 & 8,2 \\
3 & 30 & 1,4 \\
Mais de 3 & 50 & 2,4 \\
Não identificados & 1 & 0,0 \\
\hline total & 2091 & 100,0 \\
\hline
\end{tabular}

Nesse aspecto houve também similaridade entre as teses e as dissertações, notando-se predominância significativa de citações com autoria individual nos dois conjuntos. $\bigcirc$ padrão de autoria individual no presente estudo foi bem maior do que o observado recentemente na ciência da informação em geral, fato demonstrado no estudo de Bohn (2003) que encontrou 58, 15\% de artigos de autoria individual.

\section{Vida média dos documentos citados}

A vida média dos documentos citados foi de seis anos, obtida por meio da subtração das datas de defesa das teses ou dissertações, da data de publicação do documento citado. Esse dado se manteve tanto nas teses quanto nas dissertações. A fim de analisar as datas de publicação das citações, foram determinados intervalos de freqüência, usando o conceito de amplitude*. Esta foi calculada a partir da diferença entre o ano de publicação do documento mais recente (valor máximo) e o mais antigo (valor mínimo), resultando num intervalo de 9 anos. Os dados apresentados na Tabela 3 revelam uma concentração no período que vai de 1971 a 1997 , com $84,9 \%$ das citações, que se mantém mesmo quando se analisam as teses e dissertações separadamente.

Chamou atenção o número de citações do ano de 1982 (144), quando sobressairam referências a trabalhos de dois eventos. Trabalhos do $11^{\circ}$ Congresso Brasileiro de Biblioteconomia e Documentação, cujo tema foi "Biblioteca e educação permanente" foram

\footnotetext{
*Diferença entre o valor máximo e o valor mínimo, também chamado de intervalo. (http://www.webcalc.com.br/frame.asp?pag=http:/ /www.webcalc.com.br/matematica/estatistica.html).
} 
citados 30 vezes. Trabalhos do Seminário Nacional de Bibliotecas Escolares, promovido pelo extinto Instituto Nacional do Livro (INL), foram citados 18 vezes. Nesse evento foi apresentado o Modelo Flexível para um Sistema de Bibliotecas Escolares, da OEA, documento que está entre os mais citados ( 11 vezes).

Tabela 3. Ano de publicação dos documentos citados.

\begin{tabular}{ccc}
\hline Intervalo/anos & $\mathbf{n}^{\circ}$ de ref. & $\%$ \\
\hline $1926-1934$ & 3 & 0,1 \\
$1935-1943$ & 6 & 0,3 \\
$1944-1952$ & 24 & 1,1 \\
$1953-1961$ & 36 & 1,7 \\
$1962-1970$ & 103 & 4,9 \\
$1971-1979$ & 457 & 21,9 \\
$1980-1988$ & 675 & 32,3 \\
$1989-1997$ & 642 & 30,7 \\
$1998-2005$ & 109 & 5,2 \\
indefinidos & 36 & 1,7 \\
\hline Total & 2091 & 100,0 \\
\hline
\end{tabular}

Idioma das citações

português predominou, como língua de 82,1\% das citações, refletindo a origem geográfica das teses e dissertações analisadas. $\bigcirc$ inglês apareceu em segundo lugar, mas com pouca representatividade $(11,8 \%)$. Embora haja exigência legal de domínio de duas línguas estrangeiras para os candidatos aos programas de doutorado (sendo que para o mestrado só é exigida uma), não houve diferença significativa na quantidade de citações estrangeiras das teses $(20,3 \%)$ e das dissertações $(17,1 \%)$. Nesse aspecto, observou-se uma diferença nas citações em francês: $3,8 \%$ nas teses e $1,1 \%$ nas dissertações. As exigências legais de domínio de língua estrangeira para ingresso nos cursos de pósgraduação no Brasil não estão resultando em utilização significativa de literatura estrangeira por mestrandos e doutorandos, como pode ser observado na Tabela 4.

Tabela 4. Idioma dos trabalhos citados.

\begin{tabular}{lcc}
\hline \multicolumn{1}{c}{ Língua } & $\mathrm{n}^{\circ}$ de ref. & $\%$ \\
\hline Português & 1717 & 82,1 \\
Inglês & 246 & 11,8 \\
Espanhol & 89 & 4,3 \\
Francês & 33 & 1,6 \\
Italiano & 2 & 0,1 \\
Não identificados & 4 & 0,2 \\
\hline Total & 2091 & 100,0 \\
\hline
\end{tabular}

No estudo de Vianna e Caldeira (2005) verificou-se uma porcentagem mais alta de citações em português $(94,6 \%)$.

País de origem das citações

Coerentemente com os dados relativos à língua e à origem geográfica do corpus documental analisado, a maioria dos documentos citados foi do Brasil $(79,63 \%)$, o que reflete o enfoque em temas locais. Em seguida, com percentagens bem menores, vieram os Estados Unidos com 6,55\%, a França (2,34\%) e o Reino Unido (2,30\%). A Tabela 5 lista os países de publicação das citações.

Tabela 5. Países de publicação dos documentos citados.

\begin{tabular}{lcc}
\hline \multicolumn{1}{c}{ Países } & $\mathrm{n}^{\circ}$ de citações & $\%$ \\
\hline Brasil & 1665 & 79,63 \\
EUA & 137 & 6,55 \\
França & 49 & 2,34 \\
Argentina & 37 & 1,77 \\
Reino Unido & 48 & 2,30 \\
Portugal & 33 & 1,58 \\
Não identificados & 35 & 1,67 \\
Espanha & 23 & 1,10 \\
Canadá & 18 & 0,86 \\
Austrália & 12 & 0,57 \\
México & 12 & 0,57 \\
Colômbia & 5 & 0,24 \\
Países Baixos & 4 & 0,19 \\
Índia & 3 & 0,14 \\
Cuba & 1 & 0,05 \\
Dinamarca & 1 & 0,05 \\
Guatemala & 1 & 0,05 \\
Hungria & 1 & 0,05 \\
Itália & 1 & 0,05 \\
Japão & 1 & 0,05 \\
Noruega & 1 & 0,05 \\
Nova Zelândia & 1 & 0,05 \\
Peru & 1 & 0,05 \\
Rússia & 1 & 0,05 \\
Uruguai & 1 & 0,05 \\
\hline Total & 2091 & 100,0 \\
\hline
\end{tabular}

ranking dos países das citações foi o mesmo nas teses e nas dissertações. No estudo de Vianna e Caldeira (2005) a porcentagem de citações de documentos oriundos do Brasil foi ainda maior (94,3\%), reforçando a característica nacional da área. Nesse estudo, Portugal veio em seguida ao Brasil no ranking dos países de origem das citações (com 2,2\%), demonstrando a dificuldade de acesso dos praticantes a idiomas estrangeiros. 
A Tabela 6 mostra os 15 periódicos que contribuíram com o maior número de documentos citados, observando-se que os cinco primeiros colocados foram periódicos brasileiros, que publicam principalmente em português e que representam 35,7\% do total dos 2091 documentos analisados.

Tabela 6. Periódicos mais citados.

\begin{tabular}{lcc}
\hline \multicolumn{1}{c}{ Periódicos } & $\mathbf{n}^{\circ}$ de ref. & \% \\
\hline Revista da Escola de Biblioteconomia da UFMG & 70 & 13,8 \\
Revista de Biblioteconomia de Brasília & 43 & 8,4 \\
Revista Brasileira de Biblioteconomia e Documentação & 34 & 6,7 \\
Boletim ABDF Nova Série & 20 & 3,9 \\
Ciência da Informação & 15 & 2,9 \\
Library Trends & 15 & 2,9 \\
Cadernos do CED & 14 & 2,8 \\
Leitura: Teoria \& Pratica & 14 & 2,8 \\
Presença Pedagógica & 8 & 1,6 \\
Transinformação & 8 & 1,6 \\
Canadian Library Journal & 7 & 1,4 \\
Revista Leia & 7 & 1,4 \\
Amae Educando & 6 & 1,2 \\
Drexel Library Quarterly & 5 & 1,0 \\
Releitura & 5 & 1,0 \\
\hline
\end{tabular}

Três revistas estrangeiras (duas americanas e uma canadense) integraram o núcleo das mais citadas, reforçando a predominância do inglês como língua que aparece em segundo lugar nas citações.

As quatro revistas mais citadas eram, na época, publicadas em papel e não tinham versão eletrônica ${ }^{*}$. Nota-se que, no período em que as citações foram feitas, a publicação em meio digital na área de biblioteconomia/ciência da informação não estava consolidada no Brasil.

\section{Trabalhos mais citados}

Trinta e cinco trabalhos foram citados mais de quatro vezes, representando 10,33 \% do total das citações. Os trabalhos citados oito ou mais vezes aparecem no Quadro 3.

Quadro 3. Trabalhos que receberam oito ou mais citações.

\begin{tabular}{l|c}
\hline \multicolumn{1}{c|}{ Título } & ñ de citações $^{\circ}$ \\
\hline La biblioteca escolar: propulsora de la educación - Ruth Ann Davies & 11 \\
\hline Modelo flexível para um sistema nacional de bibliotecas escolares - OEA & 11 \\
\hline O prazer do texto - Roland Barthes & 11 \\
\hline Ordenar para desordenar: centros de cultura e bibliotecas públicas - Luiz Augusto Milanesi & 10 \\
\hline A biblioteca da escola primária e suas funções - Mary Peacock Douglas & 9 \\
\hline O que é biblioteca - Luiz Augusto Milanesi & 8 \\
\hline Biblioteca escolar no planejamento educacional - Theodolindo Cerdeira & 8 \\
\hline Miséria da biblioteca escolar - Waldeck Carneiro da Silva & \\
\hline
\end{tabular}

\footnotetext{
* Atualmente (julho de 2007) a situação dessas quatro revistas é a seguinte: a Revista da Escola de Biblioteconomia da UFMG foi substituída em 1996 por Perspectivas em Ciência da Informação, a Revista de Biblioteconomia de Brasília interrompeu sua publicação em papel e está divulgando resumos de seus artigos na internet, a Revista Brasileira de Biblioteconomia e Documentação está disponível online e o Boletim ABDF Nova Série foi extinto.
} 
Autores mais citados

Oitenta e um autores foram citados mais de três vezes, representando 29,84\% dos autores citados. Os 10 autores mais citados aparecem na Tabela 7.

Tabela 7. Autores que receberam mais de doze citações.

\begin{tabular}{lccc}
\hline \multicolumn{1}{c}{ Nome do autor } & Área de atuação & $\mathbf{n}^{\circ}$ de citações & $\%$ \\
\hline Ezequiel Teodoro da Silva & Educação & 50 & 2,15 \\
Luiz A. Milanesi & Ciência da Informação & 25 & 1,08 \\
Regina Zilberman & Educação & 23 & 0,99 \\
Paulo Freire & Educação & 21 & 0,90 \\
Walda de Andrade Antunes & Ciência da Informação & 20 & 0,86 \\
Edson Nery da Fonseca & Biblioteconomia & 16 & 0,69 \\
Raimunda Augusta de Queiroz & Biblioteconomia & 16 & 0,69 \\
Secretaria de Educação e Cultura do Rio Grande do Sul & - & 16 & 0,69 \\
Edmir Perrotti & Ciência da Informação & 15 & 0,65 \\
Mary Peacock Douglas & Biblioteconomia & 13 & 0,56 \\
\hline
\end{tabular}

Análise das áreas de atuação desses autores (feita com base em seus currículos e biografias) mostrou predominância da Biblioteconomia e Ciência da Informação (6), seguidas de Educação (3).

As 28 teses e dissertações analisadas foram orientadas por 25 professores, havendo dois que orientaram mais de um trabalho. Para verificar a influência dos orientadores foi analisado o número de vezes em que foram citados.
Observou-se que, dos 25 orientadores, 12 foram citados por seus orientandos. Desses, 10 foram também citados em algumas das teses e dissertações analisadas (Quadro 4). Um dos orientadores, embora não citado por seu orientando, o foi em outros três trabalhos. Os 12 restantes não foram citados. A influência na área de biblioteca escolar de dois orientadores (Luis Augusto Milanesi e Walda de Andrade Antunes) fica evidenciada pelo fato de terem aparecido também entre os 10 autores mais citados (Tabela 7).

Quadro 4. Orientadores citados.

\begin{tabular}{|c|c|c|c|}
\hline Orientador & $\begin{array}{c}\mathrm{N}^{\circ} \text { de teses e/ou } \\
\text { dissertações que } \\
\text { orientaram }\end{array}$ & $\begin{array}{c}\mathrm{N}^{\circ} \text { de citações que } \\
\text { receberam de seus } \\
\text { orientandos }\end{array}$ & $\begin{array}{l}\mathrm{N}^{\circ} \text { de outros } \\
\text { trabalhos } \\
\text { que } 0 \text { citaram }\end{array}$ \\
\hline Geraldina Porto Witter & 1 & 3 & 2 \\
\hline Luis Augusto Milanesi & 1 & 3 & 13 \\
\hline Magda Becker Soares & 1 & 3 & 4 \\
\hline Etelvina Lima & 1 & 2 & 5 \\
\hline Balina Bello Lima & 1 & 2 & 1 \\
\hline Walda de Andrade Antunes & 1 & 2 & 9 \\
\hline Else Benetti Marques Valio & 3 & 2 & 4 \\
\hline Juan José Mouriño Mosquera & 1 & 2 & 1 \\
\hline Sérgio Ferreira do Amaral & 1 & 2 & 0 \\
\hline Olga Molina & 1 & 1 & 0 \\
\hline Lady Lina Traldi & 1 & 1 & 1 \\
\hline
\end{tabular}




\section{CONSIDERAÇÕES FINAIS}

A produção de teses e dissertações sobre biblioteca escolar é pouco significativa no Brasil em termos quantitativos, levando-se em conta o período de tempo decorrido desde a implantação dos programas de pós-graduação no país (cerca de 40 anos) e a quantidade de teses e dissertações sobre o assunto (35). Os dados da presente pesquisa indicam que, embora tenha havido um aumento da produção nos anos de 1997 e 1998, este é um fato episódico, levando-se a concluir que o tema esteve pouco presente nas linhas de pesquisa da pós-graduação. Confirmou-se a exigüidade da produção científica da área de biblioteca escolar no Brasil. Considerando-se que as teses e dissertações são documentos que representam a pesquisa acadêmica e que deveriam veicular idéias originais ou novos olhares para a compreensão mais ampla do assunto, pode-se dizer que o volume desses documentos é insuficiente para reduzir a fragilidade conceitual do tema.

As 28 teses e dissertações analisadas neste estudo foram defendidas em 12 instituições, tendo sido orientadas por 25 professores, o que caracteriza grande dispersão. Outro indício dessa dispersão pode ser observado no fato de que, do total de 2091 documentos citados, cerca de $90 \%$ o foram menos de sete vezes, não se evidenciando fortes relações entre autores ou elos entre documentos. $O$ baixo número de citações

\section{REFER Ê NCIAS}

ALVARENGA, L. A institucionalização da pesquisa educacional no Brasil. 1996. 244f. Tese. (Doutorado em Educação) - Faculdade de Educação da Universidade Federal de Minas Gerais.

BOHN, M.C.R. Autores e autoria em periódicos brasileiros de ciência da informação. Encontros BIBLI, Florianópolis, n. 16, 2 sem., 2003. Disponível em: <http://www.encontros-bibli.ufsc.br/ Edicao 16/Bohn Autores.pdf> Acesso em: 10 ago. 2006.

BRASIL. Ministério da Educação e do Desporto. Secretaria de Educação Fundamental. Parâmetros Curriculares Nacionais. Brasília, 1997. 10v.

CAMPELLO, B. A função educativa da biblioteca escolar no Brasil: perspectivas para seu aperfeiçoamento. In: ENCONTRO NACIONAL DE PESQUISA EM CIÊNCIA DA INFORMAÇÃO, 5., 2003, Belo Horizonte. Anais... Belo Horizonte, Escola de Ciência da Informação da UFMG, 2003. CD-ROM. recebidas pelos orientadores reforça a pouca relação individual é indicadora da escassez de grupos de pesquisa na área. O conjunto desses resultados aponta, portanto, para uma ausência de marcas de relações entre os pesquisadores, indicando um espalhamento de idéias que provavelmente dificulta o fortalecimento de conceitos que sustentem a área.

Entretanto, foi possível identificar influência da Educação, comprovada pela presença 14 professores dessa área entre os 25 orientadores, de três autores da área entre os oito mais citados e de seis revistas de Educação entre as 15 mais citadas. Ressalte-se o fato de que o autor mais citado (Ezequiel Theodoro da Silva) é um pesquisador da área de Educação, com foco em leitura, tema que tradicionalmente tem sido central nas preocupações de bibliotecários que atuam em escolas, os quais colocam a promoção da leitura como sua ação principal.

Foi possível identificar algumas características no padrão de citação, a saber: média de 75 citações por trabalho, predominância do livro como material citado, de citações de documentos de autoria individual, de documentos em português e oriundos do Brasil e de periódicos brasileiros entre os mais citados. A comparação entre teses e dissertações não evidenciou diferenças significativas, esperadas em documentos que resultam de níveis diferentes de formação acadêmica. entre os autores. A alta porcentagem de autoria

MACIAS-CHAPULA, C.A. O papel da informetria e da cienciometria e sua perspectiva nacional e internacional. Ciência da Informação, v.27, n.2, p.134-140, 1998.

MARTUCCI, E.M. Rompendo o silêncio: a biblioteca escolar e a trajetória de um pesquisador. In: SEMINÁRIO BIBLIOTECA ESCOLAR ESPAÇO DE AÇÃO PEDAGÓGICA, 1. 1998, Belo Horizonte. Biblioteca escolar: espaço de ação pedagógica. Belo Horizonte: Escola de Biblioteconomia da UFMG/Associação de Bibliotecários de Minas Gerais, 1999. p.31-38. Disponível em: $<$ http://www.eci.ufmg.br/gebe/downloads/105.pdf>. Acesso em: 28 nov. 2007.

MUELLER, S.P.M.; PECEGUEIRO, C.M.P.A. O periódico Ciência da Informacão na década de 90: um retrato da área refletido em seus artigos. Ciência da Informacão, v.30, n.2, p.47-63, 2001.

NEVES, I.C.B. Pesquisa escola nas séries iniciais do ensino fundamental em Porto Alegre, RS.: bases para um desempenho 
interativo entre sala de aula e biblioteca escolar. R. Bibliotecon. \& Comum., v.8, p.91-116, 2000.

OHIRA, M.L.B.; MAIA, M.H.B.; SELL, M.A. Produção científica em Biblioteconomia no Estado de Santa Catarina. Transinformação, v.9, n.3, p.68-87, 1997.

POBLACIÓN, D.A.; NORONHA, D.P. Produção das literaturas "branca" e "cinzenta" pelos docentes-doutores dos programas de pós-graduacão em ciência da informacão no Brasil. Ciência da Informacão, v.31, n.2, p.98-106, 2002
VIANNA, M.M.; CALDEIRA, P.T. Literatura sobre biblioteca escolar: análise dos trabalhos apresentados no Seminário Biblioteca Escolar: espaço de ação pedagógica. In: SEMINÁRIO BIBLIOTECA ESCOLAR ESPAÇO DE AÇÃO PEDAGÓGICA, 3., 2004, Belo Horizonte. Anais... Belo Horizonte: Grupo de Estudos em Biblioteca Escolar da Escola de Ciência da Informação da UFMG: Associação dos Bibliotecários de Minas Gerais, 2005. p.7-33.

VIEIRA, A.S. A pós-graduação na EB/UFMG: memória e perspectivas. R. Esc. Bibliotecon. UFMG, v. 19, n. especial, p.68-76, 1990. 